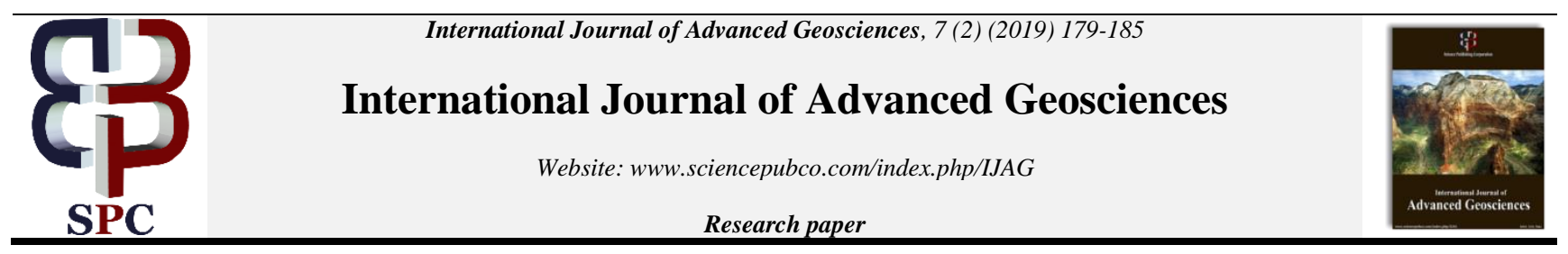

\title{
Seismic Velocity Analysis for Improved Geopressure Modelling in Onshore Niger Delta
}

\author{
Emmanuel Bassey Umoren ${ }^{1 *}$, Etim Daniel Uko ${ }^{2}$, Iyeneomie Tamunobereton-Ari ${ }^{2}$, Chigozie Israel-Cookey ${ }^{2}$ \\ ${ }^{1}$ Department of Physics, University of Uyo, Uyo, Nigeria \\ ${ }^{2}$ Department of Physics, Rivers State University, Port Harcourt, Nigeria \\ *Corresponding author E-mail: emmanuelumoren@uniuyo.edu.ng
}

\begin{abstract}
In this study, an improved evaluation of pore pressure using a model based seismic inversion technique has been carried out. Across six wells in the Onshore Niger Delta Basin, post stack seismic volume, angle stack gathers, seismic horizons, check shot, wireline logs, drilling and pressure data were analysed and interpreted. The model based inversion technique was applied to improve the seismic resolution as well as derive acoustic impedance using well velocities along with stacking velocities from velocity analysis of the 3D seismic data. Bowers $\mathrm{Vp}$-VES coefficients of 7.43 and 0.77 were used to transform the derived seismic acoustic impedance velocity into seismic pore pressure cube. The seismic acoustic impedance interval velocity reveals much of the geology and resulted to a high resolution seismic pore pressure cube when compared at well location with direct pressure data. The Derived Seismic Pore Pressure (DSPP) also revealed that pore pressure and overpressure can reach or exceed 4000 and 1000psi respectively in the field. The results obtained have demonstrated that seismic acoustic impedance volume can offer high resolution seismic pore pressure cube in both time and space.
\end{abstract}

Keywords: Niger Delta; Geopressure; Seismic Inversion; Acoustic Impedance; Seismic Velocities.

\section{Introduction}

Knowledge of formation pressure is vital to any successful hydrocarbon exploration and production program (Uko et al., 2013). This is because most petroleum producing basins, including the Niger Delta sedimentary basin have different pressure regimes (Bowers, 2002). Failure to understand these pressure variations could lead to design of well paths that increases risk and drilling hazards such as stuck pipe, pack off, excessive trip, reaming time, lost circulation, mud losses, loss of downhole equipment, extra casing, well kicks, blowouts, hole collapse etc., resulting to loss of millions of dollars of investment by exploration and production companies (Udo et al., 2015). Therefore in the over-pressured regions, accurate pore pressure prediction is very important for casing point selection and well planning. These geopressures are known to contribute to the sealing of reservoirs and their spatial distribution provides valuable information on flow paths, hydrogeology and lithology (Zhang, 2011). Correct estimation of pore pressure remains a hard task due to the difficulty in measuring pressures at depth as well as taking cores for geomechanical tests that can aid in rock stress state analysis and definition of overpressure generation mechanisms (Dutta, 2002). Typically, models based on porosity and stress values from borehole data which can be integrated with seismic data are used for pore pressure prediction (Ugwu, 2015).

Pore pressure prediction ahead of drill bit can be achieved through kinematically derived seismic velocity. The seismic velocity typically has low resolving powers for identification of various subsurface formations (Bowers, 2001). However, where high resolution velocity is used, the primary seismic input is inverted acoustic impedance which is further converted into high frequency and density for effective stress and overburden stress calculations (Sayers et al., 2002). Interestingly, both require transformation algorithms, invariably introducing additional uncertainty in the prediction of pore pressure. As a result of the pioneering work of Pennebaker (1968), stacking velocities have been used extensively with Dix (1955) algorithm for velocity estimation in pore pressure prediction. In the Niger Delta Basin, many authors have applied different methods to predict formation pore pressure. Jones (1978) applied temperature data to determine overpresuure, Osinowo et al. (2007) employed interval transit time to estimate pore pressure, Owolabi et al. (1990) employed resistivity data to estimate overpressure. In this work, we have carried out velocity analysis for improved geopressure modelling in the Onshore Niger Delta.

\section{Location and geology of the study area}

The Niger Delta Basin is situated on the continental margin of the Gulf of Guinea in equatorial West Africa between latitudes $3^{0} \mathrm{~N}$ and $6^{0} \mathrm{~N}$ and longitudes 5 and $8^{\circ} \mathrm{E}$ (Opara et al., 2011). The Basin is a wave-dominated, high energy delta with global recognition as one of the world's largest modern delta systems (Opara, 2010). It is the most prominent and leading petroleum producing sedimentary basin in Africa. The Niger Delta ranks among the world's most prolific petroleum-producing Tertiary deltas comparable to the Alaska North Slope, the Mississippi, the Orinoco and the Mahakam deltas (Reijers et al., 1997). The Niger Delta is of Tertiary age and the sub-aerial portion of the modern delta top is a complex combination of the wetlands and dry lands covering an area of approximately $75,000 \mathrm{~km}^{2}$, complemented by 
a progressive outbuilding of the delta top over $3000 \mathrm{~km}$ from its peak from inside Nigeria to its largely convex - seaward coastline (Hooper et al., 2001). The Niger Delta has an estimated area of $300,000 \mathrm{~km}^{2}$ with a large sediment volume of $500,000 \mathrm{~km}^{3}(\mathrm{Kulke}, 1995)$. The studied area is located at the onshore west region of the delta.

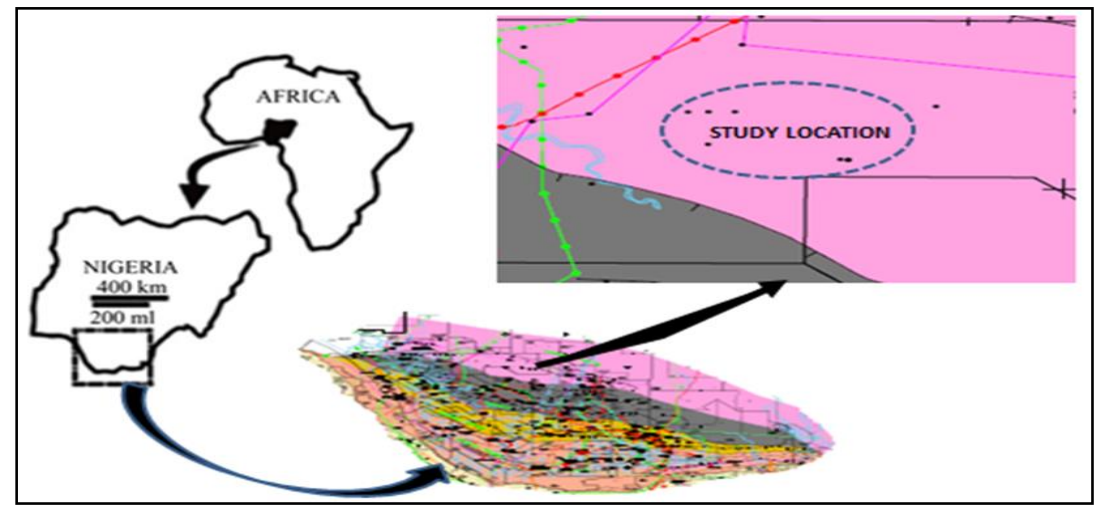

Fig. 1: Map of Study Area

\section{Methodology}

The workflow used for this study is shown in Figure 2.

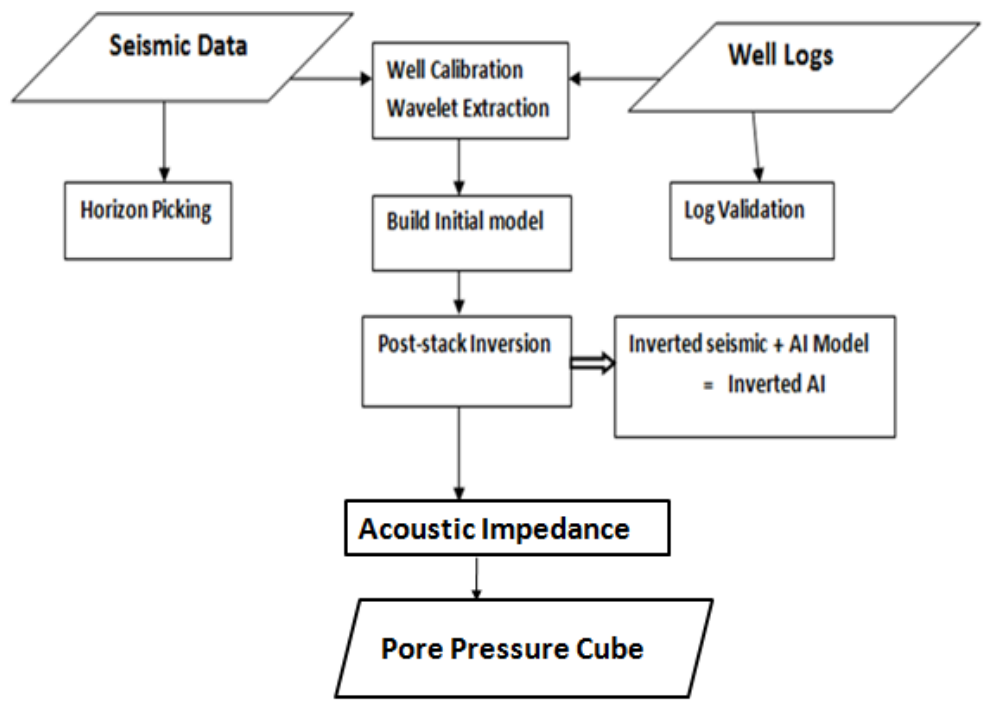

Fig. 2: Summarised Workflow for Modelling Pore Pressure Through Seismic Inversion.

\subsection{Seismic velocity analysis for accurate velocity cube}

The seismic data were conditioned and optimised before seismic inversion was performed to obtain acoustic impedance cube and subsequently seismic pore pressure volume. This step was necessary to ensure the seismic tied reasonably to the well velocities. The 3D seismic data provided for the study followed a standard processing sequence up to Post Stack Time Migration (PSTM). The velocity was optimised and constrained by relative amplitude-preserving requirements. In order to reduce uncertainty in seismic pore pressure estimation, it requires that seismic and well velocity like sonic velocity, checkshot or VSP should tie. Hence, additional sequence of data conditioning was performed using the available seismic gathers to improve the signal-to-noise ratio before attempting the inversion process. This recovered the offset-dependent frequency loss caused by NMO stretch, and align reflections with a static-based technique.

\subsection{Determination of interval velocity}

Seismic velocity data was available in the form of stacking velocities ( $V_{\text {RMS }}$ ), and was therefore converted to interval velocities ( $V_{\text {int }}$ ), the form required for seismic pore pressure prediction using the Dix Equation:

$v_{\text {int }}=\left[\frac{t_{2} v_{m s 2}^{2}-t_{1} v_{m s 1}^{2}}{t_{2}-t_{1}}\right]^{\frac{1}{2}}$

Where $t_{2}$ and $V_{\text {rms2 }}$ are the two-way travel time and rms velocity, respectively, in the lower layer and $t_{1}$ and Vrms 1 are the properties in the upper layer. The stacking angle at any given zero-offset two-way travel time (t) and offset $(\mathrm{x})$ is given by:

$$
\sin ^{2} \theta=\frac{x^{2} v_{\text {int }}^{2}}{\left[\left(v_{\text {mis }}^{2} t^{2}+x^{2}\right)\right]}
$$


Where $V_{\text {rms }}$ is the Root Mean Square (RMS) P-wave velocity at time $t$ and $V_{\text {int }}$ is the interval velocity at time, $t$ (Connolly, 1999).

\subsection{Seismic inversion}

Model-based inversion was applied to improve the low velocity field of the post stack seismic section (Figure 3) following the workflow presented in Figure 2.

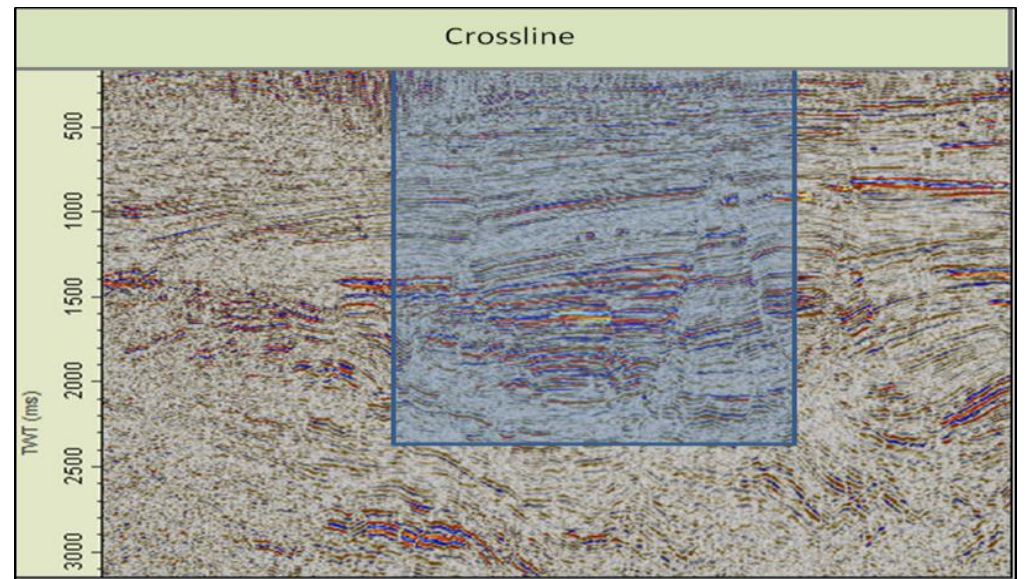

Fig. 3: The Seismic Cross Section of the Study Area Showing the Portion Used for Seismic Inversion.

The portion of the seismic section highlighted with polygon was used for the post stack seismic inversion due to the high density of wells in the area. Again, the resolution appeared high in that portion compared to the rest of the section and by using that portion, a significant system processing time was saved because inversion usually requires high computing power and several days to run if the entire volume were to be considered.

\section{Results and discussion}

In this section, the results of the wavelet extraction (Figure 4), generated synthetic seismogram (Figure 5), inversion models superimposed on the original impedance log from the well (Figure 6), inverted acoustic impedance (Figure 7), matched velocity profile from the inverted acoustic impedance and well (Figure 8 ) are presented.

More so, we have equally presented the seismically-derived interval velocity model obtained through Dix conversion before post stack seismic inversion (Figure 9), seismic acoustic impedance interval velocity after post stack inversion (Figure 10), pore pressure and overpressure predictions obtained using the seismic interval velocity before inversion (Figures 11 and 12), pore pressure and overpressure predictions using seismic acoustic impedance interval velocity (Figures 13 and 14).

From the results obtained, it is observed that estimation of formation pore pressure in the study area using the interval velocity obtained by Dix conversion (without inversion) yielded very poor results. This is because the velocity field resolution is poor, oversmoothed and originally not processed for geopressure evaluation. Hence, subsurface features are clearly not evident in Figures 9, 11 and 12 . Furthermore, the processing or modelling was not done to image subsurface pressure, hence the presence of background noise as shown in the seismic cross section (Figure 3). The quality of the stacking velocity is particularly very poor at $2000 \mathrm{~ms}$ downwards. Strong amplitude reflection is only pronounced around $1500 \mathrm{~ms}$ crossline position.

It is important to note that when velocities are taken from seismic traces, they are less accurate in the deeper and shallower sections than the middle sections because, there are relatively few traces in the shallow section. The greatest moveout and largest number of signal traces is in the middle section and the loss of high frequencies and lower moveout in the deeper section makes accurate velocities hard to pick. In this case, drift curve calibration with sonic log was adopted so as to correct for the different problems both at shallow and deep interval in the wells as the appreciable well-to-seismic match seen in Figure 8. To ascertain the accuracy of the calibrated seismic velocity field, $\mathrm{V}_{\text {int }}$ were compared with the checkshots and Sonic- $\mathrm{V}_{\mathrm{p}} \mathrm{V}_{\text {int }}$ from the wells. As checkshots use a seismic signal source so, it can be compared directly to seismic velocity data and are also immune to borehole damage, which slows the sonic log, typically shallow in the well. Second, acoustic dispersion, where for rocks, the transit times for higher-frequency ( $23 \mathrm{kHz}$ ) sonic log can be less (faster) than for lower-frequency seismic records. Subsurface imaging was therefore significantly enhanced through the post stack inversion process with results shown in Figure 10.

By applying a model-based inversion using the region highlighted with polygon in Figure 3 (the coverage area with high well penetration), the velocity field of the seismic data was greatly improved. it was therefore possible to derive useful and meaningful subsurface seismic pore pressure profile at depth which calibrated well with the measured data upon applying the velocity-pore pressure transform generated from offset sonic velocity. 


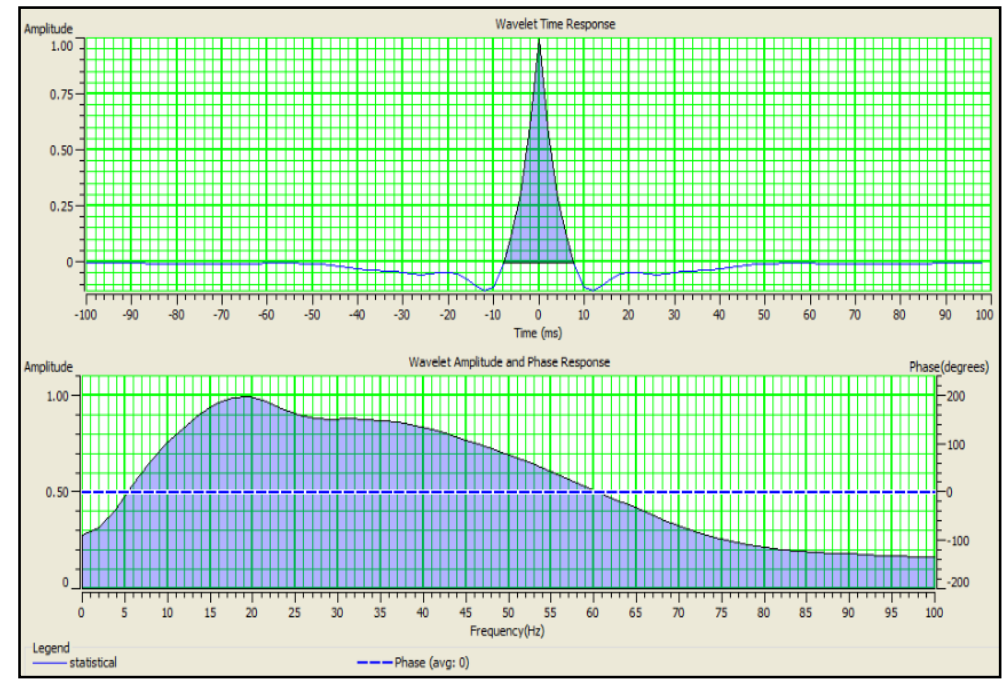

Fig. 4: Extracted Statistical Wavelet of UMO-001.

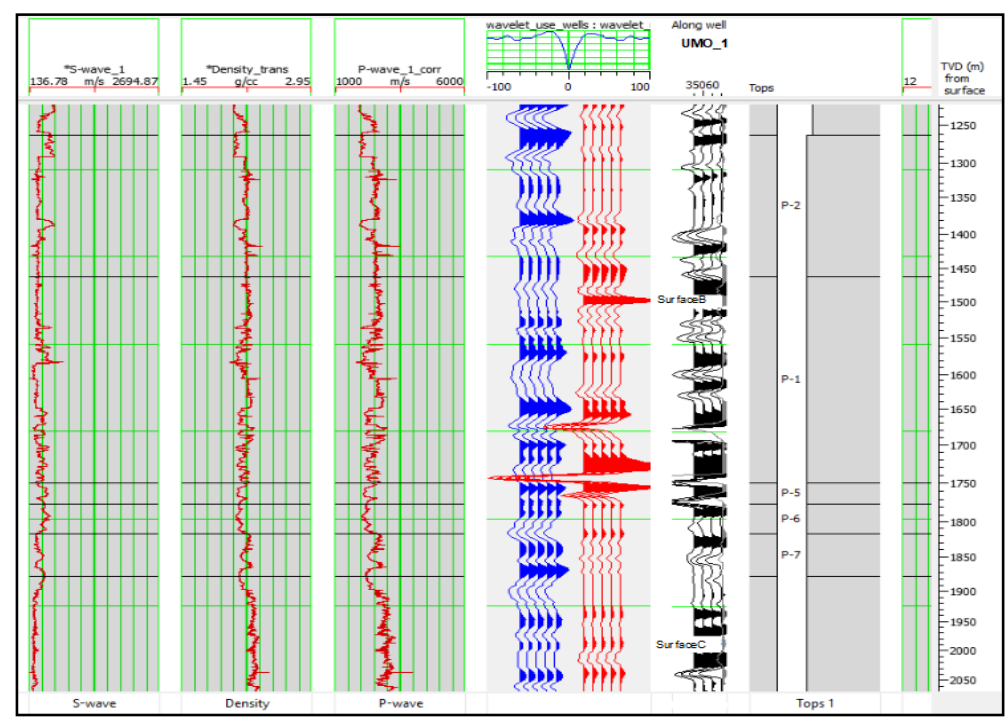

Fig. 5: Generated Synthetic Seismogram.

The blue is the synthetic while the red are the field data.

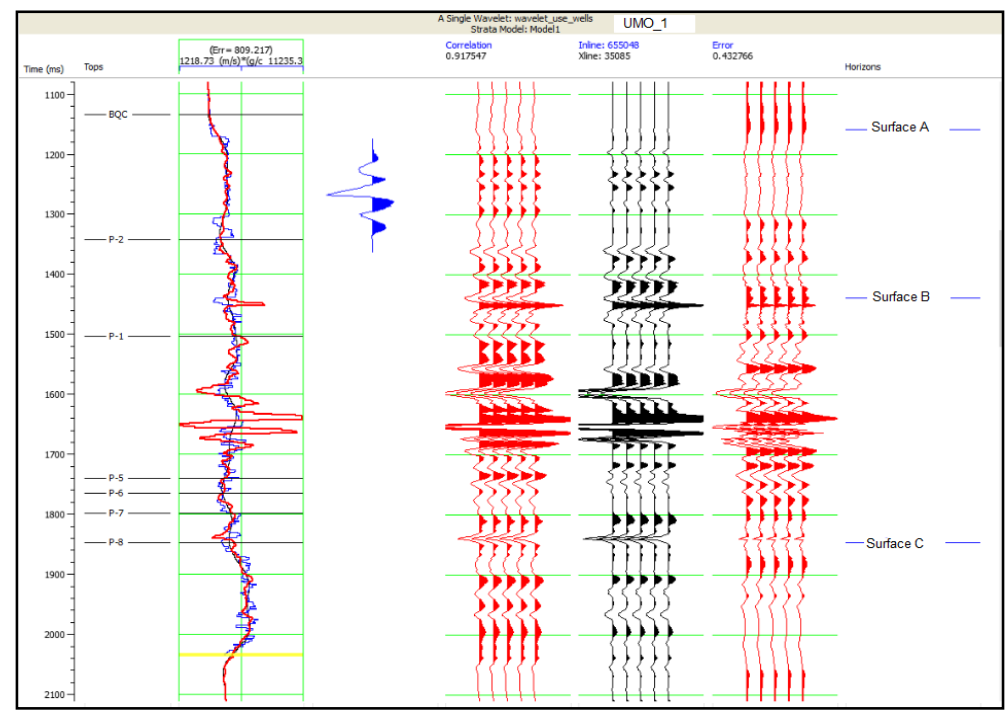

Fig. 6: Inversion Result (Red) Overlaying the Original Impedance Log from the Well (UMO_1).

From left to right, the plot shows the inversion result (red) overlaying the original impedance log from the well (UMO_1). To the right, you can see the selected wavelet (blue) and the synthetic traces estimated from the inversion result (red) followed by the original seismic composite trace (black). The error trace (right) is the difference between the previous results. The error is somewhat high but it is still within the acceptable limit (i.e. below 0.5), indicating that the inversion was mathematically correct. That is, this inversion creates a synthetic trace which matches the real trace. The error margin was reduced by repeating the process. 

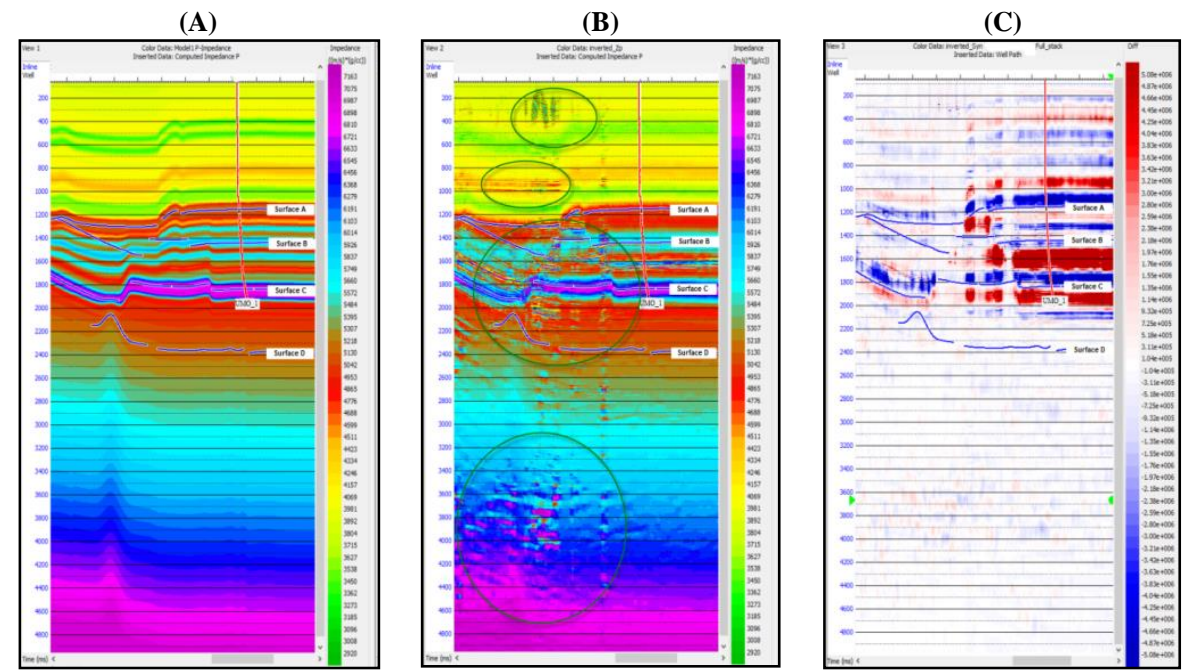

Fig. 7: Inverted Acoustic Impedance.

Figure 7a (left) is the initial background model built using UMO_1 well. The model was applied on the entire seismic volume (7c) along well path to give $7 \mathrm{~b}$ which is the computed impedance cube. There is a remarkable improvement in the resolution when Figure $7 \mathrm{~b}$ (centre) is compared with the original seismic cube. This acoustic impedance has now been made suitable for pore pressure prediction.

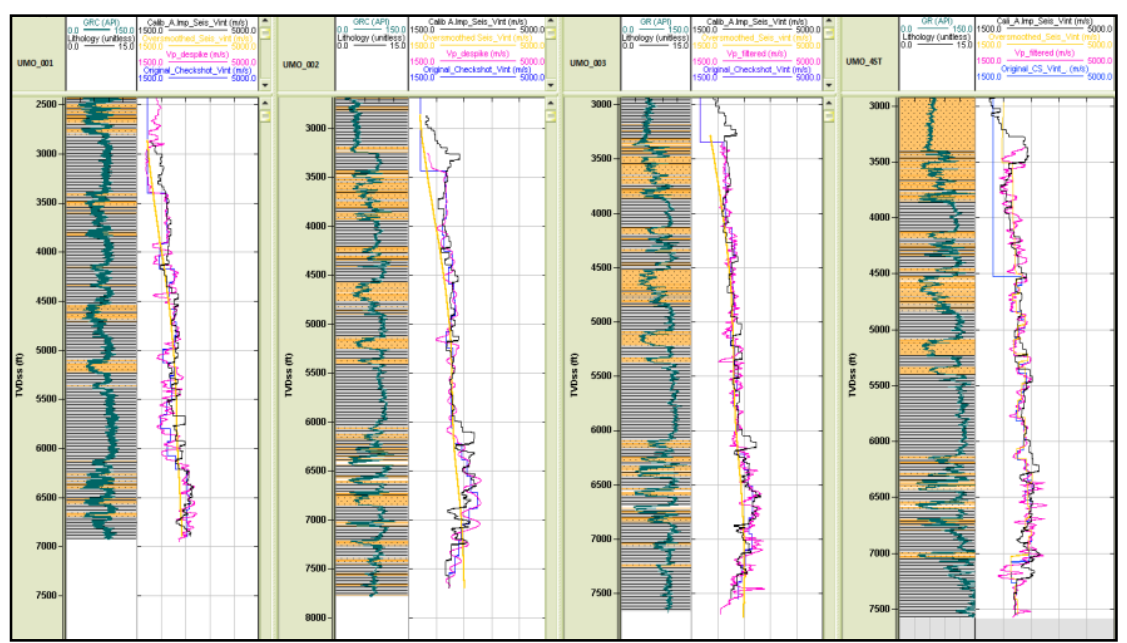

Fig. 8: Matching Velocity Profiles from Inverted AI and Well.

The yellow trend in Figure 8 is the seismic interval velocity extracted from the poor quality and oversmoothed seismic cube. The purple trend is the well velocity $\left(\mathrm{V}_{\mathrm{p}}\right)$ from sonic long which is the true vertical velocity just like the interval velocity ( $\left.\mathrm{V}_{\text {int }}\right)$ (blue) from checkshot. The black profile is $V_{\text {int }}$ extracted from the acoustic impedance cube and the close match to the well velocities is an indication of a good well-to-seismic tie achieved through adequate velocity calibration process. The lithology logs and GR revealed high net-to-gross in the wells or study area. With these correlation (comparison) there is greater confidence that the velocity field or seismic inversion is geologically correct and can thus be applied for accurate pore pressure prediction.

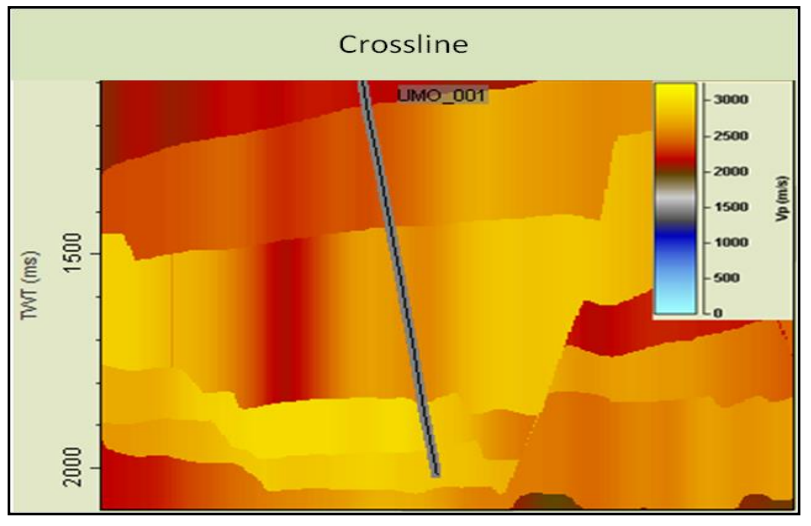

Fig. 9: Seismic Interval Velocity before Post Stack Inversion. 


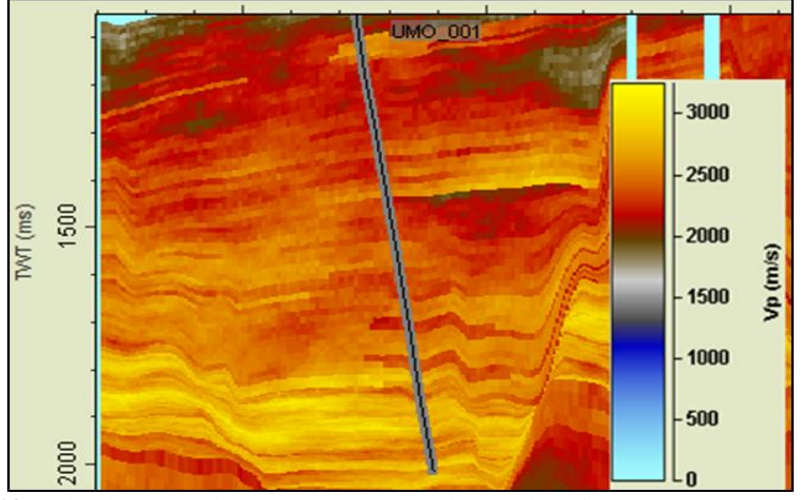

Fig. 10: Seismic Acoustic Impedance Interval Velocity after Post Stack Inversion.

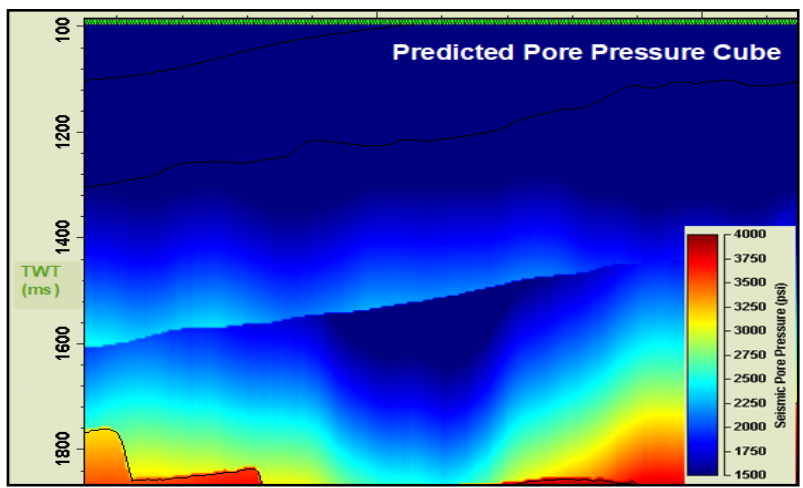

Fig. 11: Pore Pressure Cube Obtained Using the Optimised and Oversmoothed Seismic $V_{\text {int }}$. The Result Reveals Poor Imaging of the Formation Pressure as A Result of Poor Resolution.

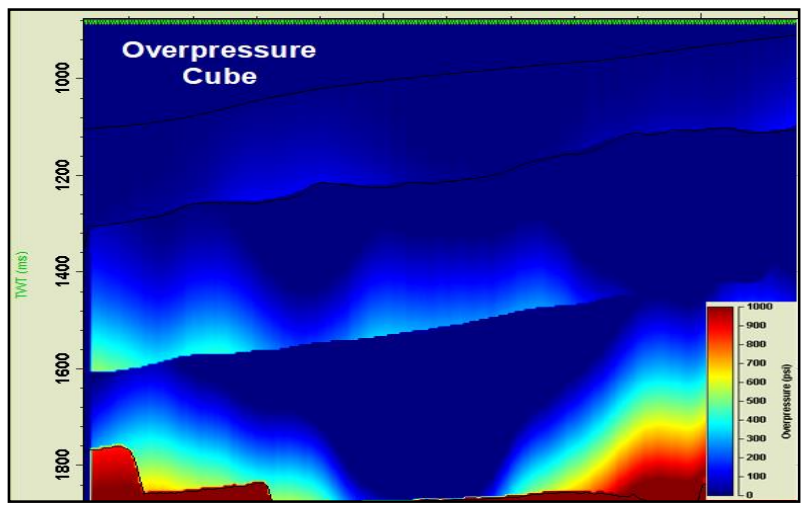

Fig. 12: Overpressure Cube Obtained Using the Optimised and Oversmoothed Seismic $V_{\text {int }}$. Compared to Figure 14, The Variation in Overpressure Could Not Be Imaged as Expected Hence, The Need for Inversion Due to Poor Resolution.

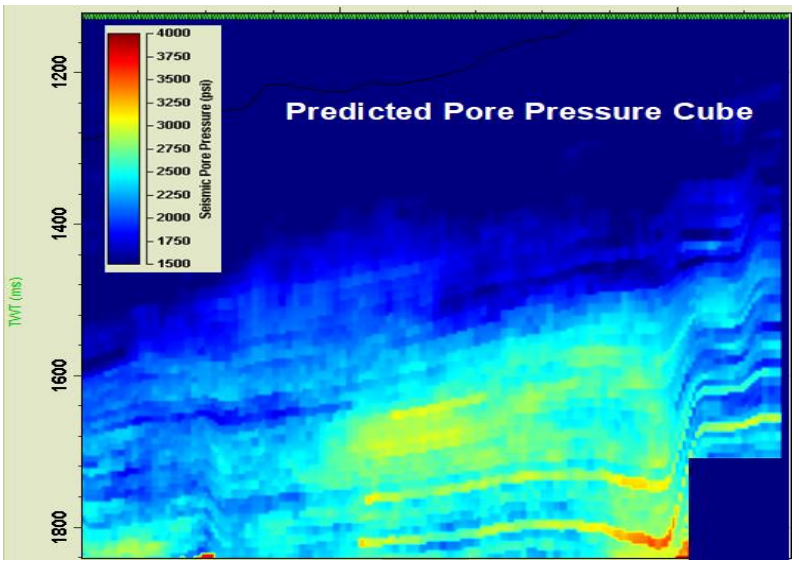

Fig. 13: Pore Pressure Cube Obtained Using the Seismic Acoustic Impedance $V_{\text {int }}$. The Zones with Dark Red Indicate Depth Interval with High Formation Pressure and It Ranges From 3000 to 4000 Psi. 


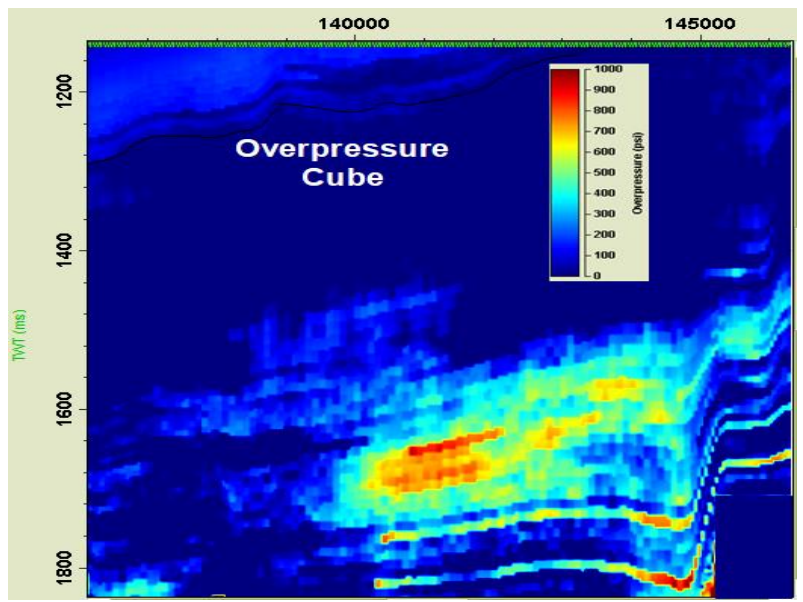

Fig. 14: Overpressure Cube Obtained Using the Acoustic Impedance $V_{\text {int }}$.

\section{Conclusion}

The seismic acoustic impedance interval velocity obtained from seismic inversion yielded a higher resolution seismic pore pressure and overpressure cubes than those gotten without inversion, when compared at well location with direct pressure data. Hence, Seismic inversion method can be relied upon to give an accurate pore pressure prediction, provided that $V_{\mathrm{p}}$-VES specific parameters have been derived for the model used, in addition to appropriate velocity analysis. The derived seismic pore pressure also revealed that pore pressure and overpressure can reach or exceed 4000 and 1000psi respectively, in the study area.

Finally, the results obtained have demonstrated that seismic acoustic impedance volume can offer high resolution seismic pore pressure cube in both time and space. Therefore, the geopressure profiles obtained from seismic acoustic impedance volume would allow oil and gas exploration industries to plan and drill prospects with confidence in the study area.

\section{References}

[1] Bowers, G. L. (2001). Determining an appropriate pore pressure estimation strategy, Offshore Technology Conference, Paper OTC 13042. https://doi.org/10.4043/13042-MS

[2] Bowers, G. L. (2002). Detecting high Overpressure. The Leading Edge, 174-177. https://doi.org/10.1190/1.1452608.

[3] Dix, C. H. (1955). Seismic velocities from surface measurements. Geophysics, 20, 68-66. https://doi.org/10.1190/1.1438126.

[4] Doust, H. \& Omatsola, E. (1990). Niger Delta. In Edwards, J. D. and Santogross, P. A., Divergent / Passive margin Basins. AAPG Memoir. American Association of Petroleum Geologists, Tulsa, OK, 48, 239-248.

[5] Dutta, N. C. (2002). Geopressure prediction using seismic data: Current status and the road ahead. Geophysics, 67 (6), $2012-2041$. https://doi.org/10.1190/1.1527101.

[6] Hooper, R. J., Fitzsimmons, R. J., Grant, N and Vendeville, B. C. (2001). The role of deformation in controlling depositional patterns in the SouthCentral Niger Delta, West Africa. Journal of Structural Geology, 24, 847 - 859. https://doi.org/10.1016/S0191-8141(01)00122-5.

[7] Jones, P. H. (1978). Problems of migration. American Association of Petroleum Geologists Bulletin, 10, 207 - 216.

[8] Kulke, H. (1995). Nigeria. In Kulke, H., ed., Regional Petroleum Geology of the World. Part II: Africa, America, Australia and Artarctica: Berlin, GebruderBorntraeger, 143-172.

[9] Opara, A. I. (2010). Prospectivity Evaluation of Usso Field, Onshore Niger Delta Basin, using 3-D Seismic and Well Log Data. Petroleum and Coal, 52(4), 308-313.

[10] Opara, A. I., Anyiam, U. O. and Nduka, A. V. (2011). 3-D Seismic Interpretation and Structural Analysis of Ossu Oilfield, Northern Depobelt, Onshore Niger Delta, Nigeria. The Pacific Journal of Science and Technology, 12 (1), 502-508.

[11] Osionowo, O. O., Oladunjoye, M. A. and Olayinka, A. I. Overpressure prediction from seismic data: implication for drilling safety. American Geophysical Union, Fall Meeting 2007, Abstract S23A - 1113.

[12] Owolabi, O. O., Okpobiri, G. A. and Obomanu, I. A. (1990). Prediction of abnormal pressure in the Niger Delta using well logs. CIM/SPE International Technical Meeting, Calgary, Canada. https://doi.org/10.2118/21575-MS.

[13] Pennebaker, E. S. (1968). Seismic data indicate depth and magnitude of abnormal pressure. World Oil, 166, 73-82.

[14] Reijers, T. J. A., Petters, S. W. \& Nwajide, C. S. (1997). The Niger Delta Basin. In Selley, R. C., ed., African Basins: Sedimentary Basins of the World. Elservier, 3, 143-172. https://doi.org/10.1016/S1874-5997(97)80010-X.

[15] Sayers, C. M., Woodward, M. J., Bartman, R. C. (2002). Seismic pore-pressure prediction using reflection tomography and 4-C seismic data. The Leading Edge, 21(2), 188-192. https://doi.org/10.1190/1.1452611.

[16] Connolly, P. (1999). Elastic impedance. The Leading Edge, April, 438-452. https://doi.org/10.1190/1.1438307.

[17] Udo, K.I, Akpan, M.J and Agbasi,O. E.(2015). Estimation of Overpressures in Onshore Niger Delta Using Wire-line Data. International Journal of Science and Research, 4 (5), 2780-2784.

[18] Ugwu, G. Z. (2015). An overview of pore pressure using seismically-derived velocities. Journal of Geology and Mining Research, 7(4), 31-40. https://doi.org/10.5897/JGMR15.0218.

[19] Uko, Etim D., Emudianughe, Juliet E. and Tamunobereton-ari, I. (2013). Overpressure Prediction in the North-West Niger Delta, using Porosity Data. IOSR Journal of Applied Geology and Geophysics, 1(3), 42-50. https://doi.org/10.9790/0990-0134250.

[20] Zhang, J. (2011). Pore pressure prediction from well logs, modification and new approaches. Earth Science Review, 108, 50-63. https://doi.org/10.1016/j.earscirev.2011.06.001. 